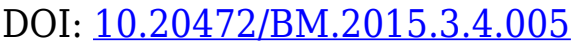

\title{
INTERNET GOVERNANCE AND ITS LEGITIMACY - FROM RETHORIC TO FACTS AND EVEN BEYOND
}

\author{
RADKA MACGREGOR PELIKANOVA, ROBERT K. MACGREGOR
}

\begin{abstract}
:
What is the Internet? What is Internet governance? Who has the competency and legitimacy for it? What are the perspectives regarding the future Internet governance? These questions deal not only with the business management of the Internet but also its compliance or contradiction with conventional approaches and perceptions. These burning questions deserve to be addressed systematically, scientifically and critically, from the standpoint of the USA, the EU and even individuals. The Meta-Analysis of the secondary data yielded from disparate literature and other sources, as well as of the primary data yielded by the author via direct questionnaires, is performed in an open-minded manner and reported comparatively, along with a number of glosses. The truth can and should be presented and explained, while myths should be corrected. The critical importance of IS/IT, and naturally of the Internet, generates a significant need for an enhanced awareness in this respect on all levels, national, regional and local, and both public and private. A successful and sustainable existence in the postmodern society depends upon the effective and efficient employment of IS/IT, and without understanding the governance of their platform par excellence, the Internet, business conduct is a chimera. The goal of this article is to address the above mentioned four questions from various perspectives through pre-set hypotheses, and to bring more light in this area, an area of a, so far, rather confused perception and much discussion. As well. to perhaps even help launch initiatives towards more involvement in GAC, ICANN and in the Internet governance as such. There is no need for myths, the truth about the Internet governance should come to light.
\end{abstract}

\section{Keywords:}

EU, DNS, Governance, ICANN, Internet

JEL Classification: H73, M15, O38

\section{Authors:}

RADKA MACGREGOR PELIKANOVA, Metropolitan University Prague, Czech Republic, Email: radkamacgregor@yahoo.com

ROBERT K. MACGREGOR, Free lance writer, USA, Email: robertkmacgregor@yahoo.com

\section{Citation:}

RADKA MACGREGOR PELIKANOVA, ROBERT K. MACGREGOR (2015). Internet governance and its legitimacy - from rethoric to facts and even beyond. International Journal of Business and Management, Vol. III(4), pp. 77-103., 10.20472/BM.2015.3.4.005 
Acknowledgement: This contribution was supported by GA ČR No. 13-02203S, "Domain Names and their significance for Business."

\section{Introduction}

Manifestly, our post-modern global society is heavily dependent on the utilization of information systems and information technologies ("IS/IT") and business conduct in the second decade of the twenty-first century is not imaginable without effectively and efficiently employing the IS/IT platform par excellence, the Internet. Optimal use of many Internet functions can easily be converted in a significant competitive advantage, while ignorance of the Internet or underestimation of its operation can easily lead to a catastrophic business result. Undoubtedly, in our knowledge-based economy, the existence of intellectual property rights should lie at the very heart of strategies for value creation (Munari, 2001)..As well, it is crystal-clear that global markets are heavily reliant upon using information and communication technology and that business conduct becomes progressively more and more "electronic". As a result, e-instruments and evenues are indispensable for the right, and rightly performed, management of private, as well as professional, affairs. Thusly, e-presentation, e-marketing and e-shopping have become critically important hallmarks of current businesses (Bílková, 2012). Consequently, modern successful and sustainable business operations entail ecommerce and other e-forms, and thus not only Internet communications, but as well edomiciliation within the Internet, is critical to success (MacGregor, 2014a).

Boldly, the Internet is a phenomenon with a dramatic impact on the economy as well as other spheres and it is critical to understand it. However, an abundance of myths, clichés and misunderstanding is attached to the Internet, its structure and governance, and it can be suggested that the imperfectness of awareness in this respect is not beneficial for individual businesses, the economy in general, and perhaps society as a whole.

The ultimate goal of this paper is to present the results of a unique and extremely complex search working with secondary data which, despite being published, did not attract much attention, nor receive proper exploration, as well as primary data collected by the author via a direct target questionnaire search. These results concern the true meaning of the Internet, the understanding of the Internet governance, the identification of subjects competent and/or legitimate for the Internet governance and the awareness of the current and future IS/IT decision makers about these issues. Namely, four hypotheses leading to four questions are addressed by this paper, and they lead to interesting conclusions calling not only for more research, but, even more, for a true move to a right understanding of the Internet governance. This is an indispensable 
condition for passing the Rubicon and for becoming truly active and powerful players on the Internet scenery, which is so important for business ....

\section{Sources and Methods}

For a scientific and critical evaluation of the Internet governance scenery, it is necessary to employ, in a particular and logical functional-systematic, a comparative, and more argumentative than axiomatic approach, employing analogy, induction and, to a restricted extent, even deduction and hypothesis (MacGregor, 2014a). A scientific approach to the Internet governance demands the identification and thorough exploration of interdisciplinary sources from a large number of countries, as well as a field search, a direct data collection (made by the author) based on questionnaires, and also practical observations. Hence, both primary sources, regarding information collected and extracted directly by the author, based on set inquires performed, based on questionnaire replies collected from current and future IS/IT decision makers, along with personal field observations, as well as secondary and already presented and so far under-analyzed and underestimated data, needed to be comparatively re-assessed with the employment of Meta-Analysis.

The conglomerate of collected and scientifically processed and logically analyzed information was scrutinized, while in particular addressing four hypotheses leading to four larger questions. Firstly, it assumed that the Internet can be clearly and universally defined (H1). Secondly, it is assumed that even the Internet governance can be clearly indentified and explained (H2). Thirdly it is assumed that all subjects competent and legitimate for the Internet governance can be determined $(\mathrm{H} 3)$. Fourthly, it is assumed that current IS/IT decision makers, as well as future IS/IT decision makers, share the same perspective regarding the first three hypotheses with the ultimate confirmation $(\mathrm{H} 4)$.

Predominantly secondary "objective" data was used to address $\mathrm{H} 1, \mathrm{H} 2$ and $\mathrm{H} 3$, while predominantly primary "subjective" data was used to address the reflection on $\mathrm{H} 1, \mathrm{H} 2$, and $\mathrm{H} 3$ by target groups. Namely, analyses and conclusions about $\mathrm{H} 1, \mathrm{H} 2$ and $\mathrm{H} 3$ dealt significantly with the outcome of scientific and academic investigation of literature, in order to define the Internet, Internet governance and for it competent and justified subjects in a generally argumentatively acceptable manner. The analysis and conclusion regarding $\mathrm{H} 4$ targeted the awareness of $\mathrm{H} 1, \mathrm{H} 2$, and $\mathrm{H} 3$ by selected homogenous relevant groups regarding information provided within the context of $\mathrm{H} 1, \mathrm{H} 2, \mathrm{H} 3$.

Regarding primary sources, it should be pointed out that a set of questionnaires and inquiries was prepared by the author and distributed to several homogenous groups of respondents. The questions targeted directly as well indirectly the perception of Intellectual property (“IP"), the Internet and Internet governance, and related key players, 
by the respondents. They included both yes/no or numeric questions leading to answers in the form of quantitative data appropriate for quantitative, as well as open-ended questions, generating answers offering personal opinions and preference statements by respondents in the form of qualitative data. Three groups of respondents were selected. The first group consisted of current IS/IT decision makers, which are IP specialists and which attended a conference entitled "Domain names and their significance for business" on $11^{\text {th }}$ April, 2014 in Prague and organized by MUP and GA ČR and CZ.Nic. The second group consisted of international IS/IT management graduate students studying under the author of this paper and the third group consisted of Czech and Slovak students considering college study of IS/IT.

Regarding secondary sources, an impressive amount of literature as well as other types of published data was used by the author of this paper. It needs to be stressed that this paper consists of critical and comparative works with information fragmentarily published from "all over", and in many languages (English, German, French, Czech) which occasionally contradict themselves or the results of the primary sources.

A major task in all areas of science is the development of theory and theoretical concepts, ultimately the production of cumulative knowledge (Schmidt, 2014) and to model a phenomenon at a deeper level (Heckman, 2005). The pathways to it entail the finding of the objectively sustainable meaning of key notions and the subjective awareness of relevant groups in this respect. The first mentioned was matched by $\mathrm{H} 1, \mathrm{H} 2$ and $\mathrm{H} 3$, and the second mentioned was matched by $\mathrm{H} 4$. The author of this paper did not succumb to the temptation to overplay the traditional strict distinction between quantitative and qualitative research and analysis, but pro-actively worked rather with Meta-Analysis. Thus the focus went towards contrasting, combining and reconciling data and results from different sources, while strictly maintaining scientific honesty, rationality and an open-minded attitude.

The resolution of conflicting information mustbe done rationally, while the solution of principles and values should ultimately depend upon the axiological distinction between good and bad (Matejka, 2013). Nevertheless, the ultimate answer regarding Internet governance needs to be pragmatic and neutral. Internet governance is not what a group thinks, or would like, rather Internet governance is what it is, and thus the goal of this paper is to find a true meaning and understanding of the Internet, Internet governance and key competent and/or legitimate players. Ultimately the rejection or confirmation of the concerned four hypotheses is just a support mechanism facilitating the improvement of the awareness in this field, which is critical for successful operations in the second decade of the twenty-first century, and doubtless even the following decades. 


\section{What is the Internet}

One set of hallmarks of the post-modern global society is information systems with information technologies („IS/IT“), information communication technologies ("ICT”) and their accelerated technological development, which changes global and local structures. The linkage of the competitive advantage to new technologies, technological skills and capabilities makes the awareness and education in this field absolutely essential (Tervonen, 2015). Boldly, ISIT, ICT and innovations in general nowadays belong to the most important factors of a modern competitive position (Ostraszewska, 2015). Another set of these hallmarks are re-occurring real or alleged crises, and the tension between integration and (dis)integration, centralization and decentralization. in this universal complexity there remain constants, desirable venues with which to successfully develop a healthy competitive environment, such as a suitable understanding and employment of the Internet (MacGregor, 2013).

The Internet, as the e-medium and platform par excellence, is a virtual network of networks, allowing packet based standardized communication and information exchanges. This impressive phenomenon is a global system built up by and in between nodes, such as computers and other network devices, and their networks, which communicate based upon relevant protocols (MacGregor, 2012b). Hence, the Internet is a global Meta-Net consisting of many nets, and built basically by two types of elements the net communication capable devices and the data communication lines, such as cables or fibers (Cichon, 2000). These nodes are server computers for hosting Websites, plain personal computers, or other IT devices able to access the Internet and communicate, and even Internet sites such as Websites. Each node has a unique numeric code address determined by protocols - Transmission Control Protocol ("TCP") an Internet Protocol ("IP"), i.e. TCP/IP. Thus these nodes and their networks communicate based upon relevant protocols, i.e. TCP/IP protocol (MacGregor, 2014a).

Along with the mentioned "tangible" structure of the Internet, there is a parallel "intangible" structure of the Internet, which consists of Top level domains ("TLDs"), each composed of sub-domains attached to hosts carrying a code address (IP numeric address) which is, for convenience, converted through the Domain Name System ("DNS"), i.e. the DNS database placed on special name computer servers, into a verbal (literal) form - a domain name (MacGregor, 2014a). The heart and cornerstone of the Internet are Root servers, which guarantee the decentralization and functionality of the tree structure of the DNS (Eberwein, 2012). The DNS as such consists of the hierarchically built Domain name space, administrative Name servers, and communicative Resolvers (Bücking, 2010). The DNS is essential for the Internet, and its design and administration evolved along with the development of the Internet (Pope, 2012). 
In action, the Internet has a number of functions - to communicate, to inform, to do business, to entertain, etc. (Köhler, 2011) and its key services include the www system, the DNS, e-mail correspondence, online communications, file sharing, social nets services, etc (MacGregor, 2014a). Clearly, the Internet is essential for e-business and ebusiness is essential for business strategy in the twenty-first century (Bílková, 2012). The Internet does not know borders and its employment in private as well as professional life looks to be limitless. However, originally, it had a much more modest guise ...

In order to fully appreciate and understand current Internet, a historical excurse is highly instructive. In 1966, the US Advanced Research Projects Agency ("ARPA"), as a subsection of the US Department of Defense ("DoD"), installed a decentralized net composed of $17 \mathrm{PCs}$ and called ARPANet, which later on became the first network implementing standard protocol communication - TCP/IP (MacGregor, 2014a). In 1969, the unofficial operation of the ARPANet, financed by the DoD, started as the first Interface Message Processor ("IMP") was installed and the first ARPANet communication occurred between UCLA the Stanford Research Institute (MacGregor, 2014a).

However, the USA had neither a monopoly nor exclusivity, nor tremendous advantages regarding networks operating based on standardization and packet transfers. It would be remiss not to mention the French Cyclades and other prophetic, often genial, projects emerging in this era. Sadly for them, even the best ideas about Internet precursors needed not only intangible efforts of wonderful experts and innovators, but as well very tangible efforts regarding material resources, namely money and computers. This was provided by the US government, but not by European states to their own experts. In addition, the common law and pioneering attitude in the US, along with the famous drive to "go for it and try it", even if the result is not certain meant another tremendous push. The US government supported the evolution towards the Internet before, as well as after the start of the private use of the Internet, especially for commercial purposes. Last, but not least, when various European e-networks projects ended, the jobless scientists were welcomed in the USA, where they continued their work, but naturally for the US networks. Louis Pouzin from France helped so much with advice for the ARPANet, that Vinton Cerf from UCLA thanked him very deeply for it (Mauriac,1998). Similar feelings could be expressed by American Microsystems, which was able to hire on Pouzin's team members, Michel Gen and Hubert Zimmermann (Mauriac, 1998). For Americans, the goal of action was to work together and connect networks while engaging all the "brains", for Europeans the goal of action was to preselect and protect one project while avoiding connections and communications with others ... well, this can be called the mortal sin in the (to be) Internet setting.

The US government has never succumbed to the temptation to politically select the "right" network and kept following the co-operative win-win sharing approach, instead of supporting a fight with an illusory goal of letting the 'best' one win and to hell with the rest. 
ARPANet and other American networks kept developing in parallel with the purpose to be compatible, to be inter-linked, i.e. to reach internetworking, as firstly described in 1974 in the Request for Comments No. 675, i.e. RFC 675 about the Internet Transmission Control Program. The internet was understood as any network using TCP/IP, and when in the late 1980s ARPANet and NSFNet were linked, the term Internet started to be used as a name for such a large and global TCP/IP network. Indeed, the move to TCP/IP translated in a dramatic increase of the population of networks (Pope, 2012).

On $1^{\text {st }}$ January 1983, ARPANet started to use TCP/IP, and so officially the Internet was born (Köhler, 2011), i.e. all networks with hosts using TCP/IP were Internet and while others, following other protocals, were mere internets. At the same time, ARPANet split and one part became the MILNet, designed for military purposes and for unclassified DoD communication (Muth, 2000), and the other part was left to private use, and especially the universities and colleges already using CSNet seized this opportunity (Naumann, 2001). The split was rather even, the 113 nodes of ARPANet were divided more or less into two halves, since 45 nodes went to the MILNet and 68 nodes remained in the reduced version of the ARPANet (MacGregor, 2014a). In 1984, the increase in the number of nodes and attached network devices and the operation of parallel networks made it virtually impossible to keep track by using some excel spread sheets to identify and match IP addresses, and a new system was introduced, the Domain Name System („DNS“), which converts a unique numeric code address into a unique verbal address and vice versa - the DNS (MacGregor, 2012b).

In 1989, the Internet reached the public as well as the private sphere, including households (Naumann, 2001) and this facilitated the start of the robust commercial use of the Internet (Muth, 2000). In 1992, Conseil Européen pour la Recherche Nucleaire ("CERN") in Switzerland developed the feature of interlinked hypertext documents that are accessed via the Internet and built on top of the DNS - Wide Web ("www"). The www is a critically important part of the Internet, which allows the public-at-large to get access to the text, audio and even video documents and information saved on various servers while using the program language Hyper Text Markup Language ("HTML"), Javascripts, and other instruments able to interpret Websites (Naumann, 2001). The information on the Website is not sent to others, instead it is posted on a server and interested third parties can reach it through a fixed Internet Address called a Uniform Resource Locator ("URL") and see it on their devices (Muth, 2000). The Internet crossed the Rubicon and changed its nature, an academic research network became a commercial network (Lindsay, 2007).

In 1995, the Internet Assigned Numbers Authority ("IANA") and the Internet Society ("ISOC") were rethinking the DNS in order to abolish the distribution and registration monopoly of the Network Solution Inc., an engineering and management consulting firm with headquarters in Herdon, Virginia ("NSI"), and to create a more effective and efficient 
dispute settlement mechanism (Köhler, 2011). The Internet became a truly commercial public medium, as the popularization of the www application facilitated the explosion of consumer and business interest in the Internet (Mueller, 2000) and the imposition of registration and renewal fees on domain names from 1995 turned NSI into a fast, easy and stable cash cow with a very low legitimacy for such an operation. This generated strong criticism, calls for a "free" and neutral Internet, and led to the emergence of the Internet Corporation for Assigned Names and Numbers ("ICANN") and to the rewording and reinforcing of the modern definition of the Internet.

Nowadays, the Internet is defined technically as the global data communication capability realized by the interconnection of public and private telecommunications networks using TCP/IP and other protocols required to implement IP inter-networking on a global scale, such as the DNS and packet rounding protocols (Mansell, 2013). The Internet is neither unified nor centralized nor operated by one subject which would be responsible for it (Cichon, 2000), instead the Internet is a free and private autonomous assembly of nets and their operators, using the same "protocol language", and thus, occasionally, the Internet is described as a modern-day form of anarchy consisting of heterogeneous blocks linked in an alternative manner. It is even suggested that it is a chaotic communications system, due to the fact that it operates without a central hierarchic administration and management structure (Muth, 2000).

Therefore, based on a thorough investigation and exploration of secondary data, as well as the historic context generated by various sources, generally of academic and technical natures, a set of satisfactory and mutually compatible definitions can be successfully extracted and on their basis the Internet can be clearly and universally defined. Thus, H1 is confirmed on this level.

Since the lack of centralization does not exclude the obvious postulate that the Internet has a solid governance and management, it is appropriate to move to the 2 nd issue and confirm or reject based on scientific data $\mathrm{H} 2$.

\section{$4 \quad$ What is the Internet governance?}

The Internet and its operation is decentralized, rather unconventional, yet highly functional and relying on communications compatibility, as well as the multi-stake holder model, etc. It is the outcome of a more than half-century long spontaneous and rather unique evolution leading to the current prima facia obscure, although explainable, Internet governance. Plainly, the nature of the Internet, with its international nature, its necessity of standardized co-operation, and its decentralized architecture and structure, makes the practice of governing a very complex proposition (Kruger, 2015).

There is no universally agreed-upon definition of "Internet governance", and several definitions are proposed, from narrowly considering the Internet governance as the 
management of and co-ordination of the technical underpinnings of the Internet, such as domain names and TCP/IP protocols, to a larger setting understanding Internet governance as a conglomerate of all factors and forces shaping the Internet and its policies (Kruger, 2015).

The understanding of Internet governance requires one to clearly set the meaning of the term governance, as such. Thus, it is essential to underline that governance is the means by which actors or elements are limited, directed and managed, and it can range from mandatory law provisions to ethical standards or self-chosen disciplines (Mansell, 2013).

Hence, Internet governance means the development and application of shared rules, principles, standards and procedures, which make the Internet structure work and evolve, and since the Internet is a network of interconnected autonomous networks, there is no one single authoritative Internet governor. Instead the governance is conducted based on decentralization and a multi-stakeholder model. However, considering the competency and responsibility, along with the structure, operation and multi-functional use of the Internet, the issue of Internet governance is dramatically important, and it would be foolish to perceive it as something insignificant or inherently exogenous.

A deeper understanding of Internet governance, especially its current stage, requires one to keep in mind the above described evolution towards, and of, the Internet, the definition of the Internet and various attitudes and (lack of) support regarding the Internet. It cannot be stressed enough that the Internet was originally a US network definitely not conceived for a massive business use, and that the legitimacy of its framework was definitely not at the center of attention (Matejka, 2013). The current Internet governance has roots in the management manner of various networks in the USA, which emerged several decades ago, based on private initiatives vehemently supported by the US government and financed from public funds. Logically, the Internet was built and developed based on US business management models fully recognizing pragmatism, a can-do attitude and a "learn-on-job" style (Kaplan, 2014) along with the typical common law preferences for business dealings and searching for win-win solutions.

The Internet is an outcome of the common law for which common law governance models are more suitable than continental law models. The Internet is definitely not an outcome of the public law sector activity in a continental law environment, and the French perception of Internet governance as a state-led mechanism, as presented in 2011 during the e-G8 summit (Mansell, 2013) appears inappropriate. Sarcastically, it could be said, that the French eagerness to decide on the state level what is the best for the Internet would continue until they would successfully manage to destroy the Internet. Further, it seems superficial to speak about just Internet governance. Instead, a myriad of aspects of the Internet are to be addressed, controlled and/or provided the stewardship by various subjects. Thus an important aspect of the Internet is governed by ICANN which manages 
and oversees DNS and IP addressing while using a multi-stakeholder model of governance based on the "bottom-up" collaborative process involving all stakeholders (Kruger, 2015) and other aspects are in the hands of other subjects employing different governance models, such as state and international organizations with their preference for intergovernmental governance models. For example, during the well-known 2005 World Summit on the Information Society ("WSIS") four Internet governance models were discussed and three of them were intergovernmental and pushed the execution of the Internet governance towards the United Nations (“UN") (Kruger, 2015).

Nevertheless, even robust sarcasm, the under-evaluation of the scattered published and not easily to be found information, and the over-playing of differences, along with the lack of an absolute and $100 \%$ agreed upon definition of the Internet governance, cannot be interpreted as sufficient facts and arguments to reject $\mathrm{H} 2$. As a matter of fact, virtually all presented opinions and statements aim in the same direction and toward a similar perception of Internet governance. Naturally, Internet governance is a more vague and less discussed phenomenon than the Internet itself, and thus the confirmation of $\mathrm{H} 2$ about the capacity to clearly identify and explain Internet governance, based on the presented secondary sources, is less intense than the confirmation of $\mathrm{H} 1$. However, what matters the most is the fact that Internet governance has a commonly, more or less, acceptable meaning, and thus it is critical to search for the lucky one or ones who has, or have, the competency and, ideally as well, the legitimacy for Internet governance, and what governance model should be prevailed. So, who is the Internetis Rex?

\section{Who has the competency and legitimacy for Internet governance?}

The Internet is gaining in importance, and the assignment of the competency for Internet governance, its legitimacy, and its practical exercise, matters. The ongoing drive and willingness of certain states and groups, even individuals, to usurp the competency, preferably the exclusive competency, for Internet governance are omnipresent, and various justifications for them are presented on an ongoing basis. The New Testament's Multi sunt vocati pauci vero electi from Matthew 22:14, i.e. many are called but few are chosen, comes to mind. This can be paraphrased regarding the Internet governance, in that many feel called to have the competency for Internet governance, and will do whatever it takes to become the one chosen, while using any and all arguments and justifications for their (alleged) legitimacy. It is highly instructive to view some subjects from this list of the "many are called", which feel that they have or should have the competency for Internet governance and are eagerly providing their reasons. Naturally, the hottest candidates are the US government and ICANN. Nevertheless, it is essential to chronologically mention as well other candidates, and their overview can start by recalling the events two decades ago, even before the creation of ICANN.

CERN brought in 1992 the www feature to the Internet, and this might be perceived as legitimacy for a certain competency, perhaps a part on the Internet governance. For 
various reasons, CERN did not go for it. However, its www invention made the Internet of Websites and URLs (Muth, 2000) a platform with an exponential growing attractiveness for the public at large. The business nature of the Internet became manifest (Lindsay, 2007) and a true war over Internet governance began and continues until today... and the Swiss are in the mix, see the presidency of the GAC!

IANA and the ISOC wanted since 1995 to change the DNS and to abolish or at least reduce the monopoly of the private corporation NSI. The NSI become competent because, based on various contracts, it was empowered to manage the distribution of domain names from lucrative TLDs, as well as to be involved in key servers management. The only legitimacy of NSI streamed out of these contracts, and thus, visá-vis the general public, especially in the global context, such a legitimacy was extremely weak and perceived rather as a de facto than ex lege or the best ethical choice. The NSI was clearly between a rock and a hard place, under the fire blowing from IANA, ISOC, etc. on one hand and under fire from various interest groups, such as omnipotent and omnipresent trademark owners associations. In addition, states did not need to remain behind. In this situation, NSI performed an extremely smart move, and decided to avoid battle and create a win-win situation. Namely, when the "privatization" of the Internet with the creation of ICANN happened, the US government, through the Department of Commerce ("DOC") made clear its will to maintain the stewardship, perhaps control, over the DNS while imposing a utility-style regulation upon NSI pricing and suggesting the reduction of NSI monopoly spheres (Mueller, 1999). Namely, NSI promised to adjust its policies, including pricing, and give away some of its competencies ... and later on really gave certain ones of them away, while maintaining the most important, at least financially, the management of the TLD .com. The win-win result was sealed when NSI was sold in 2000 to another USA corporation, VeriSign Inc, based in Reston, Virginia, which is definitely commercially successful until today. Namely, VeriSign Inc. is not only the Registry operator of the most attractive and lucrative top level domain, TLD .com, along with TLD. net and TLD .name, but as well it operates two of the Internet's thirteen root name servers. The stock VRSN is traded over USD 60 in NASDAQ while the share volume is almost 1000000 .

The International ad hoc Committee ("IAHC") emerged in 1996 as an international reaction to tensions surrounding, among others, the (doubtful) competency and (alleged) legitimacy of NSI (Kruger, 2014). Namely, IANA, ISOC, Internet Architecture Board ("IAB"), Federal Networking Council ("FNC"), the World Intellectual Property Organization ("WIPO"), the International Trademark Organization ("INTA") and the International Telecommunication Union ("ITU”) established IAHC as an international multi-organization for specifying and implementing policies and procedures relating to gTLDs, influencing the contractual registry-registrar model and a policy for resolution of TM related domain name disputes ("UDRP"), which both are employed by ICANN until today. IAHC definitely wanted to influence the distribution and execution of competencies, and probably felt 
ready even to assign or assume some of them. Well IAHC references to the multispectral support as a source for a global legitimacy did not prevail, and the IAHC itself, within one year, perished, to just partially continue as the Internet Council of Registrars ("CORE"). Well, this dual of competency against legitimacy ended with a clear victory of the first one ... and so far, the real control over key elements of the Internet structure has always translated into winning power.

ICANN was created in 1998 through a Memorandum of Understanding with DoC, shortly followed by Governmental Advisory Committee ("GAC") and until today, they are an interesting duo working against each other, as well as alongside each other, and this duo, when considered combined, has probably more power and legitimacy than any other subjects, except the US government. They emerged in the aftermath of the termination of the agreement about the DNS administration between NSI and IANA (Köhler, 2011) as the proclaimed reply to the call for privatization and the de-Americanization of the Internet. It is critical not to succumb to the rhetoric and follow the clear facts, namely that ICANN was and still is a legal entity from the private law sphere, a nonprofit Californiabased $\S 501$ (c)(3) corporation and there is not the smallest doubt that the US government was deeply involved in its formation and even thereafter in its operation (Weinberg, 2011). The statement that ICANN is entrusted with the task to represent the international community, to coordinate the Internet technical protocol and to supervise the administration of Internet Addresses and names should be understood rather as a governance proclamation (MacGregor, 2014a) than an objectively provable statement or a conclusion enjoying a consensual support. A historical overview indicates that "selfregulation" was not a coherent policy but more a rhetorical device employed by one party in the power struggle, the Internet Society, to support and make legitimate its own agenda and to preserve its own control (Mueller, 1999). According to the official version, the competencies of NSI and IANA were transferred to ICANN, and since then ICANN is the legitimate coordinator for the IP Address-systems, monitors the DNS and decides about the launching of any new TLD, develops new standards for Internet protocol and ICANN organizes the Root-Server-Systems (Köhler, 2011). However, according to many observers, ICANN was, and still partly remains dependent on the US government, and ICANN's victory over NSI was only due to the US government support and due to the fact that NSI "still got something". Namely, the profit chasing NSI managed to keep the cashcow, TLD .com, after the expiration of a five year cooperative agreement between NSI and NSF. Probably, because the US Government desired that the power battle between ICANN and NSI would end like that.

GAC is a medium for states to exercise their on ICANN and the efficiency of GAC has had a variable level. In ICANN's early years the GAC was weak, without any real power and with a low legitimacy due to the inclusion of only thirty national governments (Weinberg, 2011). However, GAC took advantage of challenging debates over many controversial Internet structure issues, such as the introduction of new gTLDs, and 
changes of various policies, as well as of the willingness of states to move from their outsider to insider status. The GAC has a particular status under the ICANN Bylaws and is presented as a mere advisory body. However, even a cursory overview of critical issues and decisions made regarding the Internet scenery in the last decade, along with the extended list of GAC members, observers and supporters, suggests that GAC can be more influential than the President/CEO and Board of directors of ICANN. This is especially true when the US Government decides to channel its "opinion" through official and more transparent mechanisms, namely via GAC. After all, a statement presented by GAC is perceived more as intergovernmental than American, even if the USA is the biggest trigger for such a statement ... and such a statement has been recently encountering an open ear and willing heart of ICANN. Nevertheless, this is a fine game and it would be plainly ignorant to perceive GAC as an agent of the US Government. The elected chair of GAC, Thomas Schneider, is from Switzerland, thus after two decades the Swiss are back, and vice-Chairs are from Argentina, Spain, Namibia, Thailand, and Turkey. Nobody from the USA and nobody from the EU ... and somebody from a country definitely challenging current Internet governance, Argentina. Well, GAC is a grey eminence hovering behind, and perhaps it is easier to identify one subject controlling the Internet than one state or group of states controlling GAC.

The UN, like GAC, is an organization of states and thus represents conventional subjects of International law. Interestingly, the UN remained for decades passive and indifferent with respect to the Internet and Internet governance and thus even at the turn of millennium it was more effective and efficient for states to attempt to influence the Internet governance via GAC than the UN. However, the UN slowly moved even in the murky waters of the Internet governance and the famous 2005 WSIS in Tunis was organized in collaboration with the UN, which presented the (in)famous Report from the Working Group on Internet Governance stating that no single government should have a prominent role in relation to international Internet governance and calling for further internationalization of Internet governance. Consequently, four models of Internet governance were proposed, three of them based on an intergovernmental approach. As a matter of fact, two models directly pushed the Internet governance from ICANN to the UN. Typically, the US fought against it and wanted to maintain the multi-stakeholder model and even more typically, the EU supported the US position, then it waffled and shifted to the UN position and as usual did not manage to maintain one voice. Ultimately an agreement, or rather a proclamation, by the US, EU, UN and 100 nations was reached according to which, the maintenance of the status quo with slight moderation toward more openness was reached (Kruger, 2015). Well, the UN did not win this round, but at least managed to become an active player within the Internet governance scenery and maintains this status through the Internet Governance Forum ("IGF").

Well, so far the chronological overview of the candidate for the chosen one for the Internet governance includes CERN, IANA, ISOC, NSI, VeriSign, WIPO, INTA, ITU, 
IAHC, ICANN and GAC, perhaps even the UN. However, the large majority of the Internet community understands very well that the backbone Internet structure went and still goes over the Atlantic, it is between the USA and the EU. New York Yankee Hall-of-Famer Lefty Gomez coined the phrase "I'd rather be lucky than good" (Gomez, 2015), and Europe has found itself good, but unlucky. Sadly, Europe had several opportunities to not only shape Internet governance but even build the Internet and missed all of them, the famous story of Louis Pouzin and Cyclades is self-explanatory (Mauriac, 1998). Even more, even international organizations representing one group, such as INTA or WIPO for trademark owners, has produced a stronger voice in the discussion over the Internet and has showed a true determination to battle in a coordinated and unified manner. Sadly, this was not the case for the European Community ("EC") and often still is not the case for the EU. It is wonderful that the post-Lisbon EU has a clearer institutional framework and manner of representation and that EU's strategy for growth Europe 2020 proclaims smart, sustainable and inclusive growth along with five ambitious goals in the areas including innovation. Nevertheless, all this looks like mere rhetoric in light of real events, such as the e-G8 summit in 2011, where French President Nicolas Sarkozy argued for tougher Internet regulation and directly clashed with representatives of other EU states, such as the UK, which were against such intrusive state-led and regulations actions with respect to the Internet (Mansell, 2013). Well, this sounds as déjà vu of 2005 WSIS. Work of the EU on Internet governance is still to a considerable extent in its infancy going through typical infant diseases, and evidence suggests that, whilst the EU has promoted itself as a leader, its performance has pointed to real constraints in fulfilling such a role. One of the key reasons for that was the uncoordinated multitude of positions and actions which caused confusion and weakened the EU position, and unfortunately the formal EU representation on the Internet governance and its vital influence on ICANN through GAC is far from being solidly established (Christou, 2013). As long as the EU does not have a consistent and harmonized attitude, then any EU attempt for more influence over the Internet governance is doomed to fail, regardless whether the EU will follow its proclaimed (not truly followed) traditional support of the principle of private sector self-regulation of the Internet (Weinberg, 2011) or not.

Last, but definitely not least, a very hot candidate for the title "master" of the Internet governance should be mentioned, the US government. The Internet evolved from a network infrastructure created by the US Department of Defense, continued to be financed by the US government and eventually the US government owned and operated (via private contractors) key components of Internet architecture, including the DNS. Apparently, the US involvement in the Internet governance became less visible and currently, the National Telecommunications and Information Administration ("NTIA") of the DoC has "just" three contractual instruments in this respect - a 2009 Affirmation of Commitment between DoC and ICANN, a contract about IP address allocation between DoC and ICANN, and a cooperative agreement between the DOC and VeriSign to 
manage and maintain the DNS root zone file (Kruger, 2015). These contractual instruments, an active role in GAC, impact on ICANN ... and most importantly consistent eagerness to go ahead with the US vision of the Internet and dormant readiness even to use for it legislative instruments and physical control over the majority of the famous 13 root name servers of DNS ... who can beat that?! Whenever the US government decided to play, it won the battle over Internet governace. The US government has retained, until today, and very likely even in the future will keep, a veto over any ICANN action pertaining to the contents of the root zone (Weinberg, 2011). At the same time, the US Government vigorously insists on the multi-stakeholder model and pushes the bottom-up approach in order to make the Internet governance as close to its users as possible. Is this mere rhetoric? Well the debates in the US Congress suggest that members of the US Government, Senate and House of Representatives mean (at least partially) this seriously, and legislative activities, such as the DOTCOM Act of 2015, are conducted in order to limit NTIA's ability to transfer its authority over certain domain name functions, and in order to maintain the "stewardship" role of the NTIA, i.e. DoC (Kruger, 2015). Well, then, should we say that Internet governance belongs to each and every one of us within a multi-stakeholder model with a bottom up approach, which is "stewarded" and not only financially supported by the US?

Well, already the length of this part of the paper and the extended number of members on the candidate list, which obviously is not exhaustive, makes the confirmation of $\mathrm{H} 3$ virtually impossible. These candidates can be categorized in the following groups: international organizations (UN, WIPO, OECD), states and governments (USA), governmental entities (GAC, IGF), Internet standards organizations (IETF, IAB, ISOC) and private organizations (ICANN). In addition, there are strong contradictions and much more opinion discrepancy than regarding $\mathrm{H}_{1}$ and $\mathrm{H} 2$. Finally, the situation is dynamically evolving and various candidates from our list are getting more and less powerful, more and less legitimate for Internet governance even within weeks. Boldly, $\mathrm{H} 1$ and $\mathrm{H} 2$ are confirmed, once sources are found and explored, we can define the Internet and Internet governance, but even exploration of a massive abundance of data about the true, alleged and (il)legitimate "Internet governors" does not allow to scientifically and objectively come to an appropriate answer. Hence, it is more than interesting to see how $\mathrm{H} 1, \mathrm{H} 2$ and $\mathrm{H} 3$ is addressed by the (alleged) key players of the Internet - competent users and IP (to be) experts advising in this field.

\section{The present and future of Internet governance from several perspectives}

Considering its complexity, diversity, and international nature, how and by whom should the Internet be governed - via a multi-stakeholder model with a bottom-up collaborative process supported by the US, OECD and some states, or via an intergovernmental model supported by the UN, IGF, Russia and other states, or via something else? However, 
what is the vox populi? What do the ultimate users and multi-stakeholder members think about the current Internet, Internet governance, key players and what do they want regarding its future? Three homogenous sets of relevant respondents were asked. Their choice reflects the fact that opinions of IP and IS/IT experts and of members of generation $\mathrm{Y}$, which exhibit an increased drive for open communications and readiness, become actively involved (Lewis, 2015) truly matters. Since the evolution of the Internet governance has been always strongly shaped by personalities, perhaps much more than states and institutions, the current Internet governance can be changed by these subjects, if they really want to do it. An appropriate method to address this issue is to go ahead and ask them. Thus, three sets of primary data were collected and analyzed in order to address directly $\mathrm{H} 4$ and indirectly $\mathrm{H} 1, \mathrm{H} 2$ and $\mathrm{H} 3$.

Firstly, regarding IP and IS/IT experts, the author of this paper proceeded via explicit ways of data collection, realized by a questionnaire survey via a questionnaire completed by a homogenous group of respondents on $11^{\text {th }}$ April, 2014 during an International conference entitled "Domain Names and Their Significance for Business" and organized by MUP, GA ČR and CZNic (MacGregor, 2014c). All of these 50 respondents were IP and IS/IT experts actively involved in Internet platforms. The questions were set in a simplified and self-controlling manner, allowing predominantly yes-no answers and not excluding additional comments. This active and explicit data indication on 50 duly completed and returned hardcopies of questionnaires was quantitatively assessed, while at the same time facilitating the employment of qualitative methods, meta-analysis and comparative critical analysis. Both qualitative and quantitative aspects were reflected (MacGregor, 2014c). The survey generated a slightly surprising result regarding the attitudes about Internet governance. 
Table 1 - Overview of answers and feedback provided by a pool of 50 IP and IS/IT experts

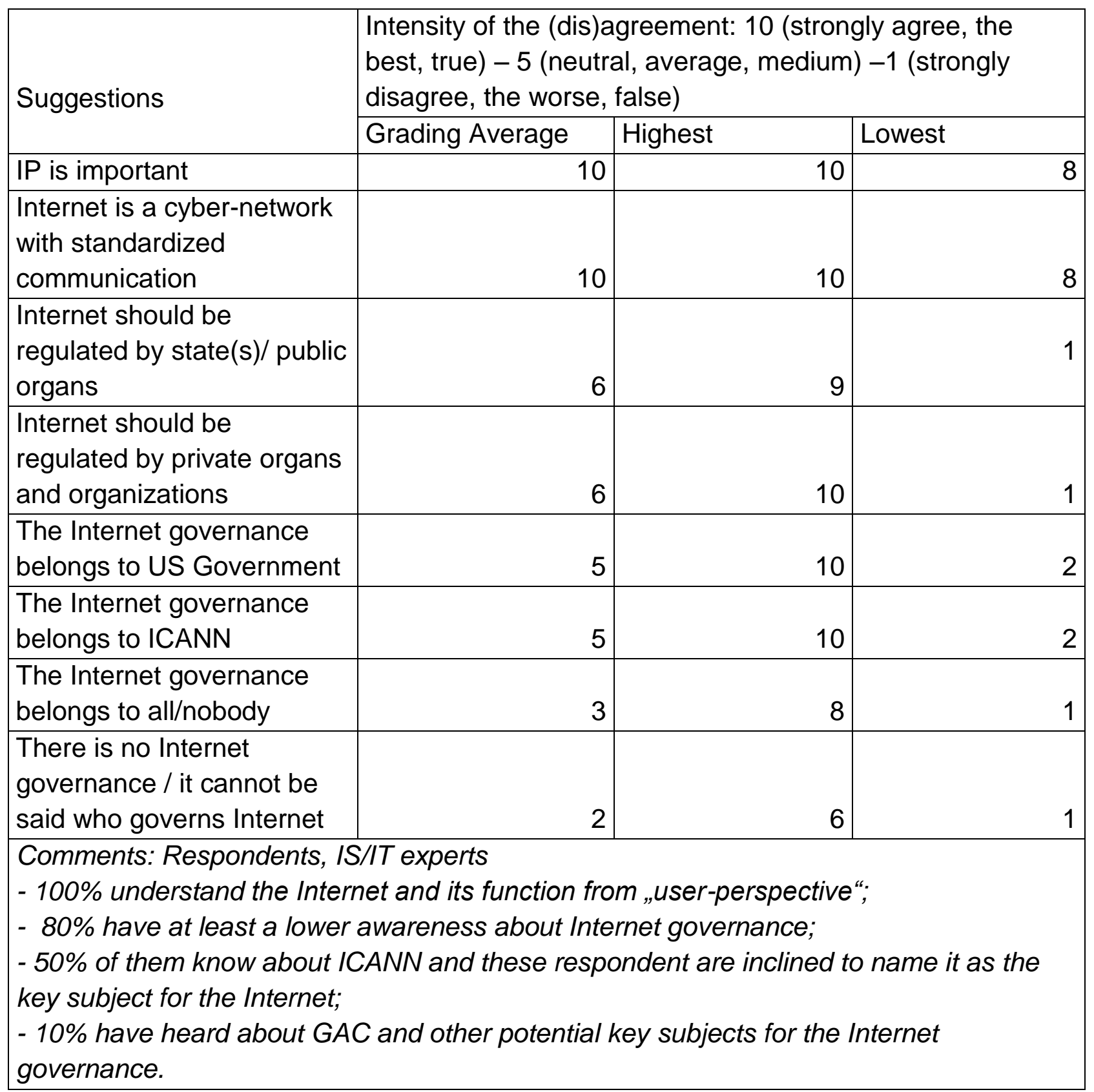

Table 1 reflects the fact that the respondents, IP and IS/IT experts, have a solid knowledge about the Internet and practical impacts of its operation and a reduced knowledge about the Internet governance setting and players. In addition, they demonstrate a high reluctance to "rock the boat" regarding the Internet governance. They are, to a certain extent, informed about current issues and deficiencies, even about the somehow shaky nature of the legitimacy of Internet governance, but since they do not 
see a reliable alternative, they do not desire to stimulate or support massive changes. The author of this paper conducted a set of additional direct interviews of various experts and top managers dealing with IS/IT, and even the yielded-up information was very similar, if not identical. Boldly, these individuals are more inclined to look for a "creative" solution within the current system, rather than to go for creative changes of the current system. They all are well aware what is at stake, and they do not desire to jeopardize the, if not fantastic, then at least decently operating status quo. For these respondents, the Internet governance should continue to be with those naturally getting to it and exercising it, the legitimacy for the Internet governance lies more in a pragmatic desire not to intrude in a correctly working system, "If it ain't broke, don't fix it" attitude, than in their belief in the multi-stakeholder model.

Secondly, regarding generation Y's opinion and their future potential to soon be IP and IS/IT experts, the author of this paper proceeded via explicit ways of data collection, realized by an anonymous questionnaire survey via a questionnaire completed by a homogenous group of her graduate college students in the spring and fall 2014 terms at the University of Life Sciences in Prague (MacGregor, 2014b). One hundred completed questionnaires were returned and a part of the generation information is indicated in Table 2. 
Table 2 - Overview of answers provided by a pool of 100 graduate "IS/IT management" students

\begin{tabular}{|c|c|c|c|}
\hline \multirow[t]{2}{*}{ Suggestions } & \multicolumn{3}{|c|}{$\begin{array}{l}\text { Intensity of the (dis)agreement: } 10 \text { (strongly agree, the } \\
\text { best, true) }-5 \text { (neutral, average, medium) }-1 \text { (strongly } \\
\text { disagree, the worse, false) }\end{array}$} \\
\hline & Grading Average & Highest & Lowest \\
\hline IP is important & 8 & 10 & \\
\hline $\begin{array}{l}\text { Internet is a cyber-network } \\
\text { with standardized } \\
\text { communication }\end{array}$ & 8 & 10 & \\
\hline $\begin{array}{l}\text { Internet should be } \\
\text { regulated by state(s)/ public } \\
\text { organs }\end{array}$ & 5 & 10 & \\
\hline $\begin{array}{l}\text { Internet should be } \\
\text { regulated by private organs } \\
\text { and organizations }\end{array}$ & 5 & 10 & \\
\hline $\begin{array}{l}\text { The Internet governance } \\
\text { belongs to US Government }\end{array}$ & 5 & 10 & \\
\hline $\begin{array}{l}\text { The Internet governance } \\
\text { belongs to ICANN }\end{array}$ & 5 & 10 & \\
\hline $\begin{array}{l}\text { The Internet governance } \\
\text { belongs to all/nobody }\end{array}$ & 3 & 10 & \\
\hline $\begin{array}{l}\text { There is no Internet } \\
\text { governance / it cannot be } \\
\text { said who governs Internet }\end{array}$ & 2 & 10 & \\
\hline $\begin{array}{l}\text { Comments: Respondents, Is } \\
\text { - } 90 \% \text { understand the Inter } \\
\text { - } 25 \% \text { have at least a lower } \\
\text { - } 10 \% \text { of them know about IC } \\
\text { key subject for the Internet; } \\
\text { - } 2 \% \text { have heard about GAC } \\
\text { governance. }\end{array}$ & $\begin{array}{l}\text { /IT management stuo } \\
\text { let and its function fro } \\
\text { awareness about Inte } \\
\text { JNN and these respo } \\
\text { and other potential ke }\end{array}$ & $\begin{array}{l}\text { ents } \\
\text { „user-perspective } \\
\text { rnet governance; } \\
\text { ndent are inclined } t \\
\text { y subjects for the Ir }\end{array}$ & $\begin{array}{l}\text { "; } \\
\text { ternet }\end{array}$ \\
\hline
\end{tabular}

The IS/IT management college students participating in the survey demonstrated a reasonable knowledge about the current Internet setting and a weak knowledge about the Internet governance, significantly lower than the experts participating in the above discussed survey. Thus, one cannot exclude that an asymmetry of information, or partially mystification, shapes their opinion. As well, the maximum spread between the highest and lowest ranking, i.e. using the entire scale, weakens the informative value of 
the generated arithmetic mean and statistical average, mode and median. It appears that generation $Y$ does not pay too much attention to the Internet governance, and even less to the labelling and rhetoric discourses about the privatization and illegitimacy. As a matter of fact, generation $Y$ is pragmatic, and perceives the discussion about the Internet governance and its legitimacy as a rather boring academic exercise without any direct practical impact. Sadly, this vision is even more noticeable by the last group of respondents.

Thirdly, regarding the opinion of generation $Y$ without (so far) any IP and IS/IT formal education, the author of this paper proceeded via explicit ways of data collection, realized by an anonamous questionnaire survey via a questionnaire completed by a homogenous group of her potential college students in spring 2015 at the Metropolitan University Prague. In total, fifty completed questionnaires were returned and a part of the generation information is indicated in Table 3.

Table 3 - Overview of answers provided by a pool of 50 potential college students

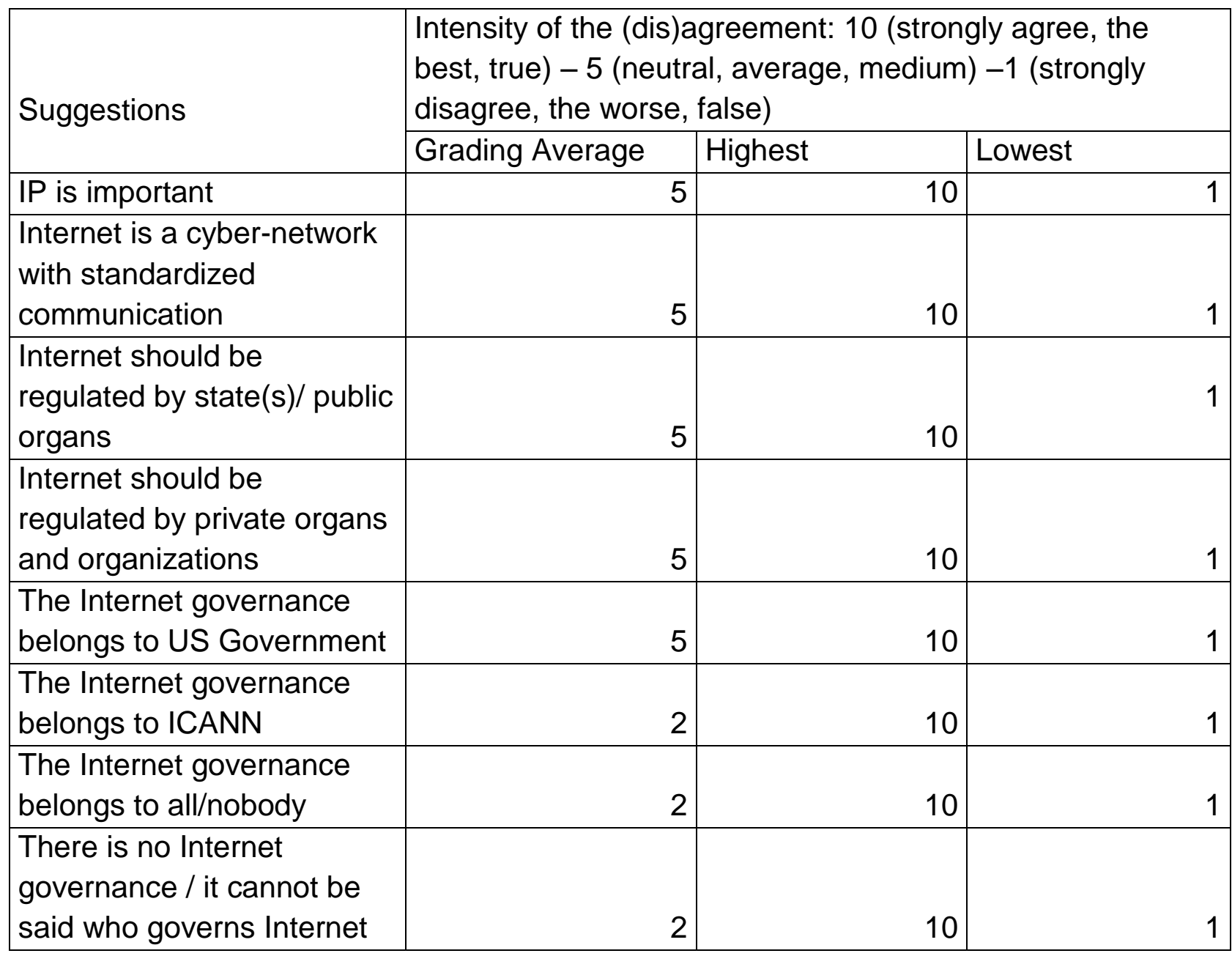


Comments: Respondents, IS/IT management students

- $50 \%$ understand the Internet and its function from „user-perspective“;

- 10\% have at least a lower awareness about Internet governance;

- $4 \%$ of them know about ICANN and these respondent are inclined to name it as the key subject for the Internet;

- 2\% have heard about GAC and other potential key subjects for the Internet governance.

The lack of knowledge about the Internet governance is manifest and it is amazing that $10 \%$ of respondents, i.e. 5 of 50 potential college students, informed that they have independently built an internet page and these respondents demonstrated an impressive awareness about setting domains, attaching internet pages to them and providing interlinking, etc. Their capacity to use the Internet is well advanced and they vigorously play Internet games, but they basically do not know the rules and have no clue who makes these rules, or why and how.

Therefore, $\mathrm{H} 4$ can be partially confirmed only regarding the understanding of the Internet, and regarding the understanding of the Internet governance and Internet "governors" must be rejected. It needs to be added that current the IS/IT decision makers have a solid knowledge about the Internet, and partially about the Internet governance, which matches (or at least gets close) to the information generated by secondary published data with respect to $\mathrm{H} 1$ and $\mathrm{H} 2$. Current IS/IT decision makers, future IS/IT decision makers and other members of generation $Y$ suffer from a dramatic information gap taking the form of ignorance and resignation regarding the Internet governance and key players. This is a very sad conclusion with a negative economic impact in the mid-term perspective. An active use of the Internet requires understanding of its governance because only this allows one to take full advantage of the Internet and to get a chance to shape the Internet according to "our" and not "their" preferences.

\section{Conclusion - Quo vadis?}

Today's big challenge isn't a lack of information, but rather it's quantity, disorganization and reduced relevancy, and indifferent resignation along with ultimate passivity. Sociologists and other experts quarrel over the study of these trends, particularly on the meaning of society and the delimitation of mutual expectations in the global and European context (Shawn, 1994). Nevertheless, there is no dispute that, in our knowledge-based economy, the identification, processing and presentation of scientifically well founded information should be followed by an open minded discussion and by a willingness to genuinely and fairly appreciate and reflect presented suggestions and statements (MacGregor, 2014b). The (not only) business success goes hand in hand with appropriate awareness, the capacity to reach an educated decision and the 
eagerness to implement them, while actively shaping the rules of the game and the game as such.

There is an abundance of literature and other published information about the meaning of the structure and functions of the Internet. Thus the confirmation of $\mathrm{H} 1$ about the possibility to identify the Internet and the capacity to find a good definition is manifestly confirmed, and even such definitions are provided in this paper. In addition, a significant part of the population, especially in developed countries, very actively uses the Internet, and thus it may appear that this practical perspective should enhance their understanding of the Internet. Well, this assumption, was partially confirmed within addressing $\mathrm{H} 4$, namely the Internet definition capacity of three tested groups reached $100 \%, 90 \%$ and $50 \%$.

There is not an abundance, but still a sufficient amount of literature and other published information about the Internet governance, its evolution and battles over it. Thus the confirmation of $\mathrm{H} 2$ about the possibility to identify the Internet capacity and the capacity to find a good definition is confirmed, and a set of suggestions regarding such definitions is provided in this paper. However this seems to be unknown to ultimate addressees. In addressing $\mathrm{H} 4$, the Internet definition capacity of three tested groups reached $80 \%, 25 \%$ and $10 \%$. This is a dramatic drop and a clear suggestion about the information asymmetry, if not a direct lack.

There is a myriad of information and statements about the "one" who does the Internet governance. However the indications generated by these sources cannot be satisfactorily reconciled. Plainly, there are way too many suggestions about who controls the Internet and often proponents of one subject do not provide sufficient arguments and do not explain why no other subjects are considered as such. The author of this paper presents a rather long list of candidates and provides comments about their true competency and legitimacy. These candidates are heterogonous from the US government over the public GAC, the semi-private ICANN, to each user of the Internet. The manner of the application of the concept of multi-stakeholder, along with the privatization rhetoric, fails to bring more light into this, as well. Hence, the H3 must be rejected, and this rejection is done based on secondary sources as well as by a primary search via $\mathrm{H} 4$. As a matter of fact, the majority of respondents have never heard about ICANN, GAC, etc.

Since $\mathrm{H} 1$ and $\mathrm{H} 2$ are confirmed and $\mathrm{H} 3$ and $\mathrm{H} 4$ rejected, the definition of the Internet and Internet governance is provided, an non exhaustive list of candidates for Internet governance presented, the asymmetric information of professional and young public discussed - is this all to satisfy the stated goal? Well, it would be remiss not to mention that one reason for the current confusion and resignation in getting a more robust knowledge about Internet governance and its governors is the undergoing conceptual power battle. What should prevail? Form over content or content over form? Power de 
iure or de facto? Status quo or to be status quo? Natural law or positive law... or mere politic or economic power? Well, good governance is effective and efficient, thus making the operation of the Internet smooth, legitimate and acceptable. The governance method must reflect on what is to be governed. The Internet is free, open, neutral, decentralized, virtual, modern, innovative. At the same, the Internet is standardized and protocolized, established in a certain manner and there is a strong resistance, if not an invulnerability, to dramatically reshape the Internet governance. Certainly, the Internet does not know state borders, but this does not imply in any manner that the Internet is beyond the reach of law, or that the Internet governance escaped the principles for business management. The Internet and its governance are well established in a common law self-regulatory manner, while distinct self-regulatory trajectories in Europe and the US are developed (Newman, 2004). Europe and the USA are already well on their way towards different regional based IS/IT strategies, and no dramatic abrupt changes in the Internet governance are to be expected in the near future. Is this fair and legitimate? Rather yes than no. It has been already proven that that universalism and benevolence are linked to the recognition of the importance of cooperation, and perhaps sustainability (Málovics, 2015), and it is truer yet in the setting of networks of networks needed to be compatible and using the same protocol. In other words, the Internet is not about a selective exclusion and knowing-better proclamation. The Internet was created by Americans more than by anyone else, and Americans have always kept it open to others, provided key common law features and multi-stakeholders model are observed, and stayed away from using the Internet for political battles. After all, network neutrality has come to serve as an all-embracing term for policy matters relating to the Internet and matches with the architecture of the Internet (Mansell, 2013). This does not look to change, fortunately! As a matter of fact, the US Congress is closely monitoring it and is ready to step in if really necessary. Fine, so what is the ultimate conclusion?

The ultimate message of this article is that it is doable and useful for each and every active user to understand Internet governance, to know who are the lucky ones on the list of Internet governance and that their positions are not perfectly and entirely legitimately established, and to be aware that, at this point, the multi-stakeholder formula coupled with open ICANN calls, meetings and conferences provide a reasonably accessible venue to "get on board“. Regarding Internet governance, it has always been the case that pressure by those with influence and power gets results, and that the proclaimed multi-stakeholder model operates rather as a model leading to a bargaining model of governance (Weinberg, 2011). Innovativeness, awareness about IS/IT and their effective and efficient employment are important factors of pro-competitive development and not only economists but as well EU officials know it (Pawlas, 2014) and the Internet governace and impact on it matters. So vigilantibus iura scripta sunt, the vigilant players have the right and, at the very end, the Internet governance is about building together and not just hanging on or around. Being innovative, open-minded and ready to get involved with the Internet governance does not have to involve considerable 
expenditures, and often low costs along with ideas, ingenuity and improvisation can bring a great result (Ostraszewska, 2015) and stear in the right strategic direction (Málovics, 2015). The US Congress plays an important role overseeing NTIA's stewardship of the DNS and the Internet governance as such, and definitely does not want to support abrupt changes or risk the operation of the system. The US government, ICANN, GAC and many organizations and individuals currently involved in the Internet guidance are looking for eager, active, responsible and educated allies, they want a responsible, transparent and communication friendly Internet governance. So let's get involved!

\section{References}

BíLKOVÁ, Renáta, DVOŘÁK, Jiří (2012). Possibilities in advancement of e-shop. In Scienitific papers of the University of Pardubice. Series D, Faculty of Economics and Administration, Vol. 25(3), pp. 30-41.

BÜCKING, Jens, ANGSTER, Henrik M (2010). Domainrecht. 2nd Edition. Stuttgart, Germany : Kohlhammer Druckerei, 222 S., ISBN 978-3-17-019820-3.

CHRISTOU, Geore, SIMPSON, Seamus (2013). The international governance of the Internet In : JØRGENSEN, Knud E., LAATIKAINEN, Katie V. (ed.). Routledge Handbook on the European Union and International Institutions : Performance, Policy, Power. London, UK : Routledge, pp. 344-356. ISBN 9780415539463,0415539463

CICHON, Caroline (2000) CICHON, Caroline. Internetverträge. Köln, GE : Verlag Dr.Otto Schmidt, 370 S. ISBN 3-504-68024-5.

EBERWEIN, Helgo (2012). Wettbewerbsrechtliche Aspekte von Domains und Suchmaschinen - Die Rechtslage in Deutschland und Österreich. 1.Auflage. Baden-Baden, GE : Nomos Verlag, 242 S. ISBN 978-3-8329-7890-7.

GOMEZ, Lefty (2015). Baseball almanac. Available at http://www.baseballalmanac.com/quotes/quolgom.shtml Retrieved on 21st May, 2015.

HECKMAN, James J. (2005). The Scientific Model of Casuality. Sociological Methodology, Vol. 35, pp.1-98. ISSN 0081-1750.

KAPLAN, Andreas (2014). European management and European business schools: Insights from the history of business schools. European Management Journal, Vol. 32(4), pp. 529-534.

KÖHLER, Markus, ARNDT, Hans-Wolfgang (2011). Recht des Internet. 7.Auflage. Heidelberg, GE : C.F.Müller, 336 S. ISBN 978-3-8114-9627-9.

KRUGER, Lennard G. (2015). Internet Governance and the Domain Name System: Issues for Congress. Congressional Research Service, CRS Report 7-5700, R42351, 6 $6^{\text {th }}$ March, 2015. Available at https://www.fas.org/sgp/crs/misc/R42351.pdf

KRUGER, Lennard G. (2014). Internet Domain Names: Background and Policy Issues. Congressional Research Service, CRS Report 7-5700, 97-868, 10 th $^{\text {th }}$ June, 2014. Available at http://fas.org/sgp/crs/misc/97-868.pdf

LEWIS, Robert. (2015), Generation $Y$ at Work: Insight from experience in the hotel sector. International Journal of Business and Management, Vol. III(1), pp. 1-17.

LINDSAY, David (2007). International Domain Name Law - ICANN and the UDRP. Oxon, UK : Hart Publishing, 489 p. ISBN 978-1-84113-584-7. 
MacGREGOR PELIKÁNOVÁ, Radka (2014a). Domain names - Their nature, functions, significance and value. Saarbrücken, GE : Lambert Academic Press, 273 p. ISBN 978-3-659-62653-1.

MacGREGOR PELIKÁNOVÁ, Radka (2014b). Selected current aspects and issues of European integration. Ostrava, CZ : Key Publishing, 2014, 186 p. ISBN 978-80-7418-226-6.

MacGREGOR PELIKÁNOVÁ, Radka (2014c). The (Dis)harmony of Opinions Regarding Domain Names in the Czech Republic. Scientific Papers of the University of Pardubice, Series D, Vol. 3(32), pp. 73-84. ISSN 1211-555x (Print), ISSN 1804-8048 (On-line). Available at http://www.upce.cz/fes/vedavyzkum/fakultni-casopisy/scipap/posledni-obsah.pdf

MacGREGOR PELIKÁNOVÁ, Radka (2013). Internet My Dearest, What Type of European Integration Is The Clearest? Acta Universitatis Agriculturae et Silviculturae Mendelianae Brunensis, Vol. 61(7), pp. 2475-2481. Permanently available at http://dx.doi.org/10.11118/actaun201361072475

MacGREGOR PELIKÁNOVÁ, Radka (2012a). And the best top level domain for European enterprises is ... International and Comparative Law Review, Vol. 12(2), pp 41-57.

MacGREGOR PELIKÁNOVÁ, Radka (2012b). New top level domains - pending success or disaster? Legal and Economic Issues of Central Europe, Vol. 1(3), pp. 75-81.

MÁLOVICS, Éva (2015). Appearance of entrepreneurial values and strategic orientations in the basic values..International Journal of Business and Management, Vol. III(1), pp. 18-35.

MANSELL, Robin (2013). Technological Innovation, Paradox and Icts: challenges for governing institutions In: Price, Monroe E., Verhulst, Stefaan and Morgan, Libby, (eds.) Routledge Handbook of Media Law. Routledge, Abingdon, Oxon, UK, pp. 501-522. ISBN 9780415683166.

MATEJKA, Ján (2013). Internet jako objekt práva - Hledání rovnováhy autonomie a soukromí. Praha, ČR : CZ.NIC, 256 s. ISBN 978-80-904248-7-6.

MAURIAC, Laurent, PEYRET, Emmanuèle...(27.3.1998). Et la France ne créa pas I'Internet. Libération. Available at http://archive.wikiwix.com/cache/?url=http://ecrans.liberation.fr/ecrans/1998/03/27/et-lafrance-ne-crea-pas-l-internet-cyclades-est-le-projet-francais-qui-aurait-pu-avoir-le-memesucc_231404\&title=\%5B3\%5D

MUNARI, Federico, ORIANI, Raffaele (2011) The economic value of Patents - Methods and Applications. $1^{\text {st }}$ ed. Cheltenham, UK : Edward Elgar Publishing Limited, 392 p. ISBN 978-1-84844-548-2.

MUELLER, Milton (2000). Technology and Institutional Innovation: Interent Domain Names. International Journal of Communication Law and Policy, Iss. 5, pp.1-32.

MUELLER, Milton (1999). ICANN and internet governance. Sorting thorugh the debris of "self-regulation.“ The Journal of Policy, Regulation and Strategy for Telecommunications, Information and Media, Vol. 1, No. 6, pp. 497-520.

MUTH, Susanne (2000). Die Bestimmung des anwendbaren Rechts bei Urheberrechtsverletzungen im Internet. Frankfurt am Main, GE : Verlag Peter Lang, 217 S. ISBN 3-631-35809-1.

NAUMANN, Tino (2001). Präsentationen im Internet als Verstoß gegen $\S \S 1,3$ UWG. Frankfurt am Main, GE : Verlag Petr Lang, 154 S. ISBN 3-631-37317-1. 
NEWMAN, Abraham L., BACH, David (2004). Self-Regulatory Trajectories in the Shadow of Public Power: Resolving Digital Dilemmas in Europe and the U.S. Governance: An International Journal of Policy, Administration, and Institutions, Vol. 17 (3), pp. 387-413. Available at http://www18.georgetown.edu/data/people/aln24/publication-12373.pdf

OSTRASZEWSKA, Zuzanna, TYLEC, Agnieszka (2015). Reverse Innovation - How it works. International Journal of Business and Management, Vol. III(1), pp. 57-74.

PAWLAS, Iwone (2014). Competitiveness of the Polish economy against the background of other European Union member states. Selected issues. International Journal of Business and Management, Vol. II(3), pp. 71-91.

POPE, Michael B., WAKRKENTIN Merrill, MUTCHLER, Leigh A., LUO, Xin (2012). The Domain Name System - Past, Present and Future. Communications of the Association for Information Systems, Vol. 30(1), pp. 329-346. Available at http://aisel.aisnet.org/cais/vol30/iss1/21/

SHAWN, Martin (1994). Global Society and International Relations: sociological concepts and political perspectives. Cambridge, UK : Polity Press, 197 p. ISBN 0745612121.

SCHMIDT, Frank L., HUNTER, John E (2015). Methods of Meta-Analysis - Correcting Error and Bias in Research Findings. $3^{\text {rd }}$ Edition, London, UK : SAGE, 2014, 640 p. ISBN 978-145-228-689-1.

TERVONEN, Pekka, HAAPASALO, Harri (2015). A creating business from innovations - Essentials mission of intermediate organization. International Journal of Business and Management, Vol. III(1), pp. 119-131.

WEINBERG, Jonathan (2011). Governments, Privatization, and Privatization: ICANN and GAC. Michigan Telecommunications and Technology Law Review, Vol. 18(1), pp. 188-218. 